\title{
The Two-Week Rule for NHS Gastrointestinal Cancer Referrals: A Systematic Review of Diagnostic Effectiveness
}

\author{
Kymberley Thorne*,1, Hayley A. Hutchings ${ }^{\#, 1}$ and Glyn Elwyn ${ }^{\#, 2}$ \\ ${ }^{I}$ Centre for Health Information, Research \& Evaluation, School of Medicine, Swansea University, Swansea, UK \\ ${ }^{2}$ Department of Primary Care and Public Health, Cardiff University, Cardiff, UK
}

\begin{abstract}
Aim: To systematically review the impact of the Two-Week Rule in increasing the pick-up rate of colorectal cancers and Upper Gastrointestinal (GI) cancers in the NHS.

Materials and Methods: Data were combined for meta-analyses to determine (1) the Two-Week Rule pick-up rate for each cancer type and (2) the proportion of patients referred using the Two-Week Rule. Overall results were given as weighted averages.

Results: There were 20 articles and 27 peer-reviewed abstracts included in this review. Colorectal Cancer: Only $9.5 \%$ of patients referred by the Two-Week Rule were eventually diagnosed with colorectal cancer $(\mathrm{n}=24)$. When examining the referral origin of all colorectal cancer patients diagnosed during the time of 19 studies with this data, 32.2\% had been referred using the Two-Week Rule. Upper GI Cancer: Only 5.5\% of patients referred by the Two-Week Rule were eventually diagnosed with Upper GI cancer $(\mathrm{n}=23)$. When examining the referral origin of all Upper GI cancer patients diagnosed during the time of 17 studies with this data, 23.6\% had been referred using the Two-Week Rule.

Conclusion: The Two-Week Rule is not sufficiently effective in diagnosing neither upper GI nor colorectal cancers in patients presenting to their General Practitioner.
\end{abstract}

\section{BACKGROUND}

The Two-Week Rule (TWR) referral [1] was introduced by the UK's New Labour government in 2000 as one of many initiatives tackling the increasing problem of patients presenting to their General Practitioner (GP) with symptoms indicative of a cancer who, although urgently referred, did not get a hospital appointment in sufficient time to significantly improve their health outcome. It was hoped that the TWR referral route would help to reduce the number of cancer-related deaths by $20 \%$ in people under the age of 75 years by 2010 , thereby saving approximately 130,000 lives [2]. The scheme allowed GPs to "fast-track" these patients to shorten the length of time they waited for a diagnosis followed by potentially life saving treatment. TWR referrals were faxed to the relevant diagnostic unit using a dedicated number and an appointment was made for the patient within two weeks. Only delays due to patient choice were acceptable reasons to over-run the two week target.

Disease-specific guidelines [3, 4] were published with the aim of helping GPs make decisions about when to refer people to specialists when they presented with symptoms that could have been caused by cancer. This would facilitate the appropriate referral of suspected cancer patients using the TWR. In the case of gastrointestinal (GI) cancers, the referral guidelines applied to upper GI cancers (UGCs) including oesophageal and gastric cancer, and colorectal cancers (CRCs).

*Address correspondence to this author at the Centre for Health Information, Research \& Evaluation, School of Medicine, Swansea University, Swansea, UK; E-mail: k.thorne@swansea.ac.uk

"These authors contributed equally to this work.
In 2006 we published a systematic literature review, reporting that the CRC pick-up rate for the TWR referral for suspected CRC patients was only $10.3 \%$ [5]. However, this figure was based on a meta-analysis using only eight peerreviewed articles published at the time. We now offer a more comprehensive review by updating the original search with recent evidence and by altering the inclusion criteria to include eligible peer-reviewed abstracts into the meta-analysis. We have also extended our updated review to include UGCs for the first time.

\section{METHODS}

A literature search was performed using Pubmed and the Cochrane Library employing a text search for peer-reviewed research articles. The search terms used were "colorectal", "CRC", "upper gastroint*", "upper GI", "gastrointestinal", "oesophageal" and "gastric" in combination with "urgent referral*", "two week*", "2-week*", "fourteen day*" and "fast track". In addition to this, all peer-reviewed abstracts presented at the internationally renowned British Society of Gastroenterology (BSG) conferences since published in Gut journal supplements since 2000 were hand-searched to locate suitable abstracts for inclusion in the meta-analyses. The lead author of this review did all literature searching and article assessments using pre-defined search and inclusion criteria agreed by all authors.

Only peer-reviewed studies commenting on the effectiveness of the TWR in diagnosing GI cancers were selected. Studies performed in non-NHS organisations were excluded. Studies were also excluded if they had no comparable data to contribute to the meta-analysis. Where a research article also had a peer-reviewed abstract by the same author on the same 
topic, the research article was used in the review and the abstract was excluded.

Data describing the TWR GI cancer pick-up rate and the proportion of GI cancer patients diagnosed using the TWR identified were extracted and split according to cancer type (UGC or CRC). Data extracted were actual values. Data were extracted into the following four outcomes for analysis: (1) $\mathrm{N}^{0}$ TWR referrals received; (2) $\mathrm{N}^{0}$ cancers diagnosed from the TWR referrals; (3) Total $\mathrm{N}^{\mathrm{o}}$ cancers diagnosed during the study period (irrespective of referral route) and (4) the $\%$ of all cancers diagnosed that were referred by the TWR. Outcomes 1 and 2 are used to calculate the cancer pick-up rate for each study (\%) by each study author. Many go on to compare the number of TWR-referred cancers with the total number of cancers diagnosed using outcomes 2 and 3 to calculate outcome 4 . Where one of the outcomes was not reported in the article but it could be calculated using the other three values, the authors of this article did that calculation and used that figure for analysis. All studies with comparable datasets were combined to give overall results for both cancer types, given as weighted averages.

We further split the articles retrieved according to two time periods: those conducted between Jan 2000 and Dec 2002 (Group 1) and those conducted between Jan 2003 and Dec 2008 (Group 2) to determine whether GI cancer pick-up rates had improved over time. Any studies overlapping these time periods were allocated into the group where the majority of the study had taken place. Those studies with no start and end dates reported were allocated into a time period based on their publication date whereby anything published before 2003 was automatically included in Group 1 .

\section{RESULTS}

After critically appraising all articles and abstracts found in the literature search, there were 20 published research articles and 27 peer-reviewed abstracts with comparable data reporting on the effect of the TWR in NHS diagnostic services for GI cancers, of which two reported on both upper GI and colorectal cancers [6, 7]. Tables $\mathbf{1} \& \mathbf{2}$ show all raw data collected for this study split according to cancer type: CRC data (Table 1) and UGC data (Table 2).

\section{Colorectal Cancers}

The 24 CRC studies used showed that of the 11304 patients with a suspected CRC referred by their GP using the TWR, only $1070(9.5 \%)$ were subsequently diagnosed with CRC. When we split the data according to the period when the studies were conducted, we found that for the 14 Group 1 CRC studies (2000-02), only $633(11.1 \%)$ of 5654 patients referred using the TWR were diagnosed with CRC. However, the 10 Group 2 CRC studies (2003-08) reported that only $437(7.7 \%)$ of 5650 patients referred using the TWR were diagnosed with CRC.

When determining the referral route of all CRC patients diagnosed during the time of the 18 studies reporting this data, we found that only 1116 of the 3461 (32.2\%) CRC patients diagnosed during the study periods were referred by GPs using the TWR. When we examined the data split according to time period, we found that 560 of 1782 (31.4\%) of CRC patients in the nine Group 1 studies had been re- ferred using the TWR compared with 556 of 1679 (33.1\%) of nine Group 2 studies.

\section{Upper GI Cancers}

The 23 UGC studies identified for this analysis showed that for the 7855 patients referred by their GP using the TWR for a suspected UGC, only $431(5.5 \%)$ were actually diagnosed with one, either oesophageal or gastric. When data was split according to time period we found that for the 17 Group 1 UGC studies, of 6322 patients referred using the TWR, only $319(5 \%)$ were diagnosed with a UGC whilst the six Group 2 UGC studies, 112 (7.3\%) of 1533 patients referred using the TWR were diagnosed with UGC.

When examining the proportion of UGCs diagnosed via the TWR, we found that 338 of 1431 (23.6\%) patients in 17 studies had been referred using the TWR. When we split the data according to period of study, we found that 171 of 933 (18.3\%) of UGC patients from 10 studies in Group 1 had been referred using the TWR, compared with 167 of 498 (33.5\%) of patients with UGCs in seven Group 2 studies.

\section{DISCUSSION}

For each type of GI cancer, the overall cancer pick-up rate by the TWR was less than $10 \%$ (CRC $=9.5 \%$ and UGC $=5.5 \%)$. However, when the data was split according to the period when the studies were conducted, we found that Group 1 CRC pick-up rates were higher than Group 2 pickup rates (11.1\% vs $7.7 \%)$, whilst Group 1 UGC pick-up rates were lower than those of Group 2 (5\% vs $7.3 \%$ ). The overall proportion of CRC patients who had been referred via the TWR was $32.2 \%$ and showed a slight increase when data was split according to time period: $31.4 \%$ for Group 1 and $33.1 \%$ for Group 2. The overall proportion of UGC patients who were referred via the TWR was $23.6 \%$. However, when data was split according to time period, we found that only $18.3 \%$ were diagnosed via the TWR in Group 1, compared with $33.5 \%$ in Group 2.

This paper reviewed all relevant peer-reviewed evidence from studies reporting on the impact of the TWR on NHS services. All datasets have been included from all eligible studies for analysis, making this review as comprehensive as possible. However, there were a limited amount of peerreviewed research articles in this field, with only 20 publications meeting our inclusion criteria and containing comparable, eligible datasets. For this reason we opted to include peer-reviewed abstracts presented at the BSG conferences since 2000. There was a wealth of information contained within these abstracts, published in annual supplements by the Gut journal, but very few ever made it to publication as a research article. Wherever they did, for the purpose of this review the article was used instead of the abstract.

There were three studies, all focussing on UGC patients, which did their own "two-stage" studies where they retrospectively examined the success of the TWR in diagnosing cancer at two distinct time points [44, 48, 51]. Kapoor et al. reported a decrease in the UGC pick-up rate for the TWR from $3.8 \%$ for the period July 2000 - Feb 2002 to $2.9 \%$ for the period March 2002 - Feb 2003 [44]. However, there were relatively similar numbers of TWR referrals in both groups, even though the time frame for the second stage study was only 12 months compared to the 18 months indicated for the 
Table 1. Data Extracted for Meta-Analysis Relating to CRC Patients from 27 Studies. Entries are Listed Chronologically According to Publication Date. Where Data was not Present in the Article, the Corresponding Box(es) were Greyed Out

\begin{tabular}{|c|c|c|c|c|c|c|c|c|c|}
\hline Lead author & Ref. & $\begin{array}{l}\text { Article type } \\
(1=\text { article; } \\
2 \text { = abstract })\end{array}$ & $\begin{array}{l}\text { Study start } \\
\text { date } \\
(\mathbf{m m m}-\mathbf{y y})\end{array}$ & $\begin{array}{l}\text { Study end } \\
\text { date } \\
(m m m-y y)\end{array}$ & $\begin{array}{l}N^{0} \text { TWR } \\
\text { referrals }\end{array}$ & $\begin{array}{c}\mathrm{N}^{0} \text { cancers } \\
(\%)\end{array}$ & $\begin{array}{l}\text { Total } N^{0} \text { cancers } \\
\text { diagnosed during } \\
\text { the study period }\end{array}$ & $\begin{array}{c}\% \text { cancers } \\
\text { diagnosed } \\
\text { via TWR }\end{array}$ & $\begin{array}{l}\text { Time period } \\
(1=2000-02 ; \\
2=2003-08)\end{array}$ \\
\hline \multirow[t]{2}{*}{ Stone } & \multirow[t]{2}{*}{ [8] } & 2 & Jan-00 & Sep-00 & 264 & $37(14)$ & & & 1 \\
\hline & & 2 & Jan-00 & Sep-00 & 105 & $26(24.8)$ & & & 1 \\
\hline Stoker & [7] & 2 & NA & NA & 151 & $18(11.9)$ & & & 1 \\
\hline Debnath & [10] & 1 & Aug-00 & Jul-01 & 237 & $21(8.9)$ & 96 & 21.9 & 1 \\
\hline Walsh & [11] & 1 & Aug-00 & Oct-00 & 78 & $8(10.3)$ & 38 & 21.1 & 1 \\
\hline Chaudri & [13] & 2 & NA & NA & 243 & $15(6.2)$ & & & 1 \\
\hline Flashman & [14] & 1 & Jul-00 & Jun-01 & 758 & $65(8.6)$ & 249 & 26.1 & 1 \\
\hline Trickett & [15] & 1 & Nov-00 & Oct-01 & & 30 & 147 & 20.4 & 1 \\
\hline Barwick & [16] & 1 & Jan-01 & Aug-01 & 144 & $14(9.7)$ & & & 1 \\
\hline Davies & [17] & 1 & Nov-99 & Oct-02 & 2294 & 257 (11.2) & 635 & 40.5 & 1 \\
\hline Glancy & [18] & 1 & Aug-00 & Nov-01 & 326 & $32(9.8)$ & & & 1 \\
\hline Chohan & [19] & 1 & Jul-00 & Dec-01 & 462 & 64 (13.9) & 195 & 32.8 & 1 \\
\hline Barrett & {$[24]$} & 1 & Jan-02 & Dec-02 & & 43 & 154 & 27.9 & 1 \\
\hline Rao & [25] & 1 & Jun-03 & Dec-03 & 319 & $14(4.4)$ & 54 & 25.9 & 2 \\
\hline Smith & [26] & 1 & Jan-02 & Dec-04 & 2748 & $174(6.3)$ & 478 & 36.4 & 2 \\
\hline John & {$[27]$} & 1 & NA & NA & & 43 & 100 & 43 & 2 \\
\hline Aljarabah & {$[28]$} & 2 & Apr-06 & Sep-06 & 217 & $22(10.1)$ & & & 2 \\
\hline \multirow[t]{2}{*}{ Rai } & \multirow[t]{2}{*}{ [29] } & 1 & NA & NA & 222 & $14(6.3)$ & 88 & 15.9 & 2 \\
\hline & & 1 & NA & NA & 1000 & $100(10)$ & 400 & 25 & 2 \\
\hline Shaw & [30] & 1 & Sep-05 & Sep-06 & 204 & $12(5.9)$ & & & 2 \\
\hline Bevis & {$[31]$} & 1 & Oct-02 & Sep-04 & & 97 & 193 & 50.2 & 2 \\
\hline John & [32] & 1 & Apr-04 & Mar-05 & 534 & $60(11.2)$ & 175 & 34.3 & 2 \\
\hline
\end{tabular}


Table 2. Data Extracted for Meta-Analysis Relating to Patients with UGC from 22 Studies. Entries are Listed Chronologically According to Publication Date. Where Data was not Present in the Article, the Corresponding Box(es) were Greyed Out

\begin{tabular}{|c|c|c|c|c|c|c|c|c|c|}
\hline Lead author & Ref. & $\begin{array}{l}\text { Article type } \\
\text { (1 = article; } \\
2 \text { = abstract })\end{array}$ & $\begin{array}{l}\text { Study start } \\
\text { date } \\
(\mathbf{m m m}-\mathbf{y y})\end{array}$ & $\begin{array}{c}\text { Study end } \\
\text { date } \\
(\mathrm{mmm}-\mathrm{yy})\end{array}$ & $\begin{array}{l}N^{0} T W R \\
\text { referrals }\end{array}$ & $\begin{array}{c}\mathrm{N}^{\mathrm{o}} \text { cancers } \\
(\%)\end{array}$ & $\begin{array}{l}\text { Total } \mathrm{N}^{\mathrm{o}} \text { cancers } \\
\text { diagnosed } \\
\text { during the study } \\
\text { period }\end{array}$ & $\begin{array}{c}\% \text { cancers } \\
\text { diagnosed } \\
\text { via TWR }\end{array}$ & $\begin{array}{l}\text { Time period } \\
(1=2000-02 \\
2=2003-08)\end{array}$ \\
\hline Spencer & [33] & 2 & NA & NA & 63 & $7(11)$ & & & 1 \\
\hline Mahmood & [34] & 2 & NA & NA & 45 & $2(4.4)$ & & & 1 \\
\hline Lassman & [35] & 2 & NA & NA & 79 & $12(15.2)$ & & & 1 \\
\hline Loehry & [36] & 2 & Apr-01 & Sep-01 & 79 & $3(3.8)$ & & & 1 \\
\hline $\begin{array}{c}\text { Boulton- } \\
\text { Jones }\end{array}$ & {$[6]$} & 2 & NA & NA & 280 & $27(9.6)$ & 76 & 35.5 & 1 \\
\hline Barbour & [39] & 2 & Oct-01 & Mar-02 & 172 & $17(9.9)$ & 35 & 48.6 & 1 \\
\hline Aung & [40] & 2 & Sep-00 & Dec-01 & 307 & $29(9.4)$ & 105 & 27.6 & 1 \\
\hline Reilly & [41] & 2 & Aug-00 & Jul-01 & 79 & $8(10.1)$ & 30 & 26.7 & 1 \\
\hline Radbourne & [42] & 2 & Jul-00 & Dec-01 & 153 & $16(10.5)$ & 109 & 14.7 & 1 \\
\hline Mohammed & [43] & 2 & Nov-99 & Dec-01 & & 16 & 144 & 11.1 & 1 \\
\hline \multirow[t]{2}{*}{ Kapoor } & \multirow[t]{2}{*}[44]{} & 1 & Jul-00 & Feb-02 & 1852 & $70(3.8)$ & & & 1 \\
\hline & & 1 & Mar-02 & Feb-03 & 1785 & $52(2.9)$ & & & 1 \\
\hline Spahos & [45] & 1 & Sep-00 & Aug-02 & 623 & $38(6.1)$ & 247 & 15.4 & 1 \\
\hline \multirow[t]{3}{*}{ Gera } & \multirow[t]{3}{*}{ [51] } & 2 & Jan-02 & Dec-02 & 157 & $6(3.8)$ & 57 & 10.5 & 1 \\
\hline & & 2 & Jan-05 & Dec-05 & 261 & $24(9.2)$ & 62 & 38.7 & 2 \\
\hline & & 2 & Jan-04 & Aug-04 & 175 & $16(9.1)$ & 31 & 51.6 & 2 \\
\hline Irving & [52] & 2 & Apr-07 & Apr-08 & 295 & 34 (11.5) & 53 & 64.2 & 2 \\
\hline
\end{tabular}

first stage study. Perhaps if the time periods had been more equal this decrease would not have occurred.

The remaining two studies with two-stage evaluations both showed marked increases in the UGC pick-up rate of the TWR $[48,51]$. This may have been due to the significant time period that had elapsed between the two stages of the studies - approximately three years. Both studies also reported a marked increase in the proportion of patients with UGCs being referred using the TWR compared with other routes (such as emergency or routine referrals).

The low GI cancer pick-up rate following a TWR referral suggests that the guidelines may not be effective. GPs may have inappropriately referred patients due to the incorrect interpretation or to the need to deliberately speed up diagno- ses in low-risk patients where the routine waiting list was too long due to patient pressure or other demands on NHS endoscopy services. We also acknowledge that the symptoms exhibited by patients visiting their GP can be misinterpreted as potential cancer symptoms when they are, in fact, benign GI conditions such as reflux, dyspepsia or haemorrhoids. However, this review did not aim to collect the proportion of inappropriate referrals to the TWR by each study and the proportion of those who were later diagnosed with a GI cancer so we are unable to test this hypothesis using this data.

Perhaps it is the location of these cancers that has caused these differences? UGCs have a wide range of indicative symptoms which are also present in a number of benign conditions such as reflux, dyspepsia and abdominal pain. This 
would increase the number of TWR referrals and lower the proportion of patients later diagnosed with a UGC. The same is true of CRC, with bloody stools and haemorrhoids being as common in benign conditions.

When we consider the proportion of these cancers being diagnosed via the TWR compared with other referral routes such as emergency referrals, routine referrals, etc, we see that there has been relatively little change for CRC patients, whilst the proportion of UGC patients being diagnosed via the TWR has increased over time from $18.3 \%$ to $33.5 \%$. This may be explained by the embarrassing nature of CRC means that many symptomatic patients do not present to their GPs until the latter stages [24], which tend to be too advanced to confidently predict a good outcome for the patient. UGCs do not have the same social stigma attached. Consequently, the GP has more opportunity to exercise the TWR referral in this case. Another explanation may be that emergency referrals would never see a GP to allow a TWR referral to be instigated. Those articles quoting the proportion of GI cancer patients diagnosed via the A\&E route state numbers ranging from $13.4 \%-35.3 \%$ for CRCs $[12,14,15,17,19,21,27$, $31,32]$ and from $31 \%-41 \%$ for UGCs [37, 39, 40].

In more recent articles and abstracts, the proportion of newly diagnosed CRCs not identified by the TWR can be attributed in part to the English Bowel Cancer Screening Programme which was rolled out in April 2006. Men and women aged between 60-69 years were asked to submit faecal occult blood tests (FOBTs) to their local screening unit. Any patients with positive FOBTs were referred for colonoscopy or flexible sigmoidoscopy [53]. This programme may be identifying asymptomatic CRC patients who would not then present via TWR or emergency routes, thus explaining the lack of improvement in the proportion of CRC patients identified using the TWR.

The TWR has placed a significant burden on the resources of most gastroenterology services in the NHS with little gain in identifying malignancies [54]. Most hospitals have a dedicated TWR referral list to ensure their Trust meets the strict two-week target. This should, in theory, have a negative impact on all other aspects of the service, although no evidence of this has been found to date. Three studies reported a decline in the routine endoscopy waiting lists following the introduction of the TWR [11, 25, 45], possibly due to an increased awareness of the guidelines for patient referrals, the more efficient organisation of services or the introduction of nurse endoscopists to cope with increased demand.

The effect of the TWR on long term survival remains unknown [11]. Many studies have reported no significant difference in the stage of the disease in CRC patients referred via the TWR compared with other referral routes [12, $14,19,26,31]$. This finding was supported by a study by Kiran et al., who reported that there was no relation between the duration of CRC symptoms and the stage at presentation [55]. This means that those patients with advanced stages of CRC do not necessarily become symptomatic at a particular time, so the TWR does not necessarily improve the survival of CRC patients but does reportedly reduce the number of patients presenting as emergency cases [56]. Contrary to this, one study has shown that the TWR route has more CRC patients with Duke's classification stage D (late stage) tumours than any other route $(\mathrm{TWR}=14$, outpatient clinics $=8, \mathrm{~A} \& \mathrm{E}$ = 5) [19].

When we compare the results of this review with the national cancer statistics for the UK published by Cancer Research UK, we find that age-standardised (European) mortality rates for $\mathrm{CRC}$ have decreased in both males and females between 2000 and 2006 [57]. The same decrease was seen for gastric cancer [58]. However, mortality rates for oesophageal cancer appear to have marginally decreased for females but have peaks and troughs with a marginal overall increase for males [59]. The decrease in CRC mortality cannot obviously be explained by the TWR, given the low CRC pick-up rate and the relatively small increase in the proportion of TWR-derived CRC diagnoses. However, the introduction of screening may contribute to this statistic. We reported a slight increase in UGC pick-up rates and a large increase in the proportion of UGCs being detected by the TWR. This may explain the decrease in mortality described by these statistics when we combine the trends for the mortality rates for oesophageal and gastric cancers.

We feel that the TWR has had a positive impact on the NHS as it has raised the awareness of GPs and NHS staff to refer potential cancer patients in a timelier manner to expedite their treatment and potentially improve their chances of survival, especially as this is a Government target. However, given the low cancer pick-up rates for both CRC and UGC, it is likely that the target assigned to the TWR (that the patient must be seen within 2 weeks on this system) has become more important than the reason for the referral, namely that the patients may have a cancer. We have no data on which patients were truly eligible for the TWR according to the guidelines as this data was not part of the remit of this review but it is possible that 1 ) inappropriate referrals are diluting the impact of the TWR and lowering the cancer pickup rates and 2) the guidelines are not effective enough, possibly because they are not compulsory and can be overridden by clinical judgement by the GP or because they are open to interpretation by the GP.

It may be that had further initiatives such as the Modernising Endoscopy Services Programme [60], the Global Rating Scale [61] and the 18-week target [62] not been introduced, we may have seen more resources diverted to NHS endoscopy services as they began to manage their TWR lists without detriment to the routine waiting lists.

\section{CONCLUSION}

The TWR pick-up rates reported here suggest that the TWR is diagnosing a low proportion of patients with either CRCs or UGCs. An improved way of identifying symptomatic patients as they present to their GP is required, along with a more rigorous system for validating referral guidelines to reduce the number of inappropriate referrals within the system.

\section{REFERENCES}

[1] NHS Executive. Cancer waiting times: Achieving the two week target (HSC 1999/205). Health Services Circular. NHS Executive: London 1999.

[2] Department of Health. The NHS Cancer Plan. A plan for investment. A plan for reform. Department of Health: London 2000.

[3] Department of Health. Referral guidelines for suspected cancer Guidelines. Department of Health: London 2000. 
[4] National Institute for Health and Clinical Excellence. Referral guidelines for suspected cancer (Clinical guideline 27). Guidelines. National Institute for Clinical Excellence: London 2005; Report No. CG27.

[5] Thorne K, Hutchings HA, Elwyn G. The effects of the two-week rule on NHS colorectal cancer diagnostic services: a systematic literature review. BMC Health Serv Res 2006; 6: 43.

[6] Boulton-Jones J, Gamble S, Goddard W, Long R, Teahon K. The impact and clinical appropriateness of the two week wait scheme for suspected cancer. Gut 2002; 50(Suppl 2): A398 [Abstract].

[7] Stoker E, Elsender A, Bradbury D, Cullen M, Chirnside V, Thompson N. Audit of fast track 2-week GI cancer wait. Gut 2002; 50(Suppl 2): A38 [Abstract].

[8] Stone D, Hussaini S, Mandel A, Sanz J, Villena M, Dalton H. Audit of the "two week cancer rule" for gastrointestinal malignancy. Gut 2001; 48(Suppl 1): A175 [Abstract].

[9] Moreea J, Green J, MacFie J, Mitchell C. Impact of the two week waiting time standard on the Gastroenterology Service of a District General Hospital (DGH). Gut 2001; 48(Suppl 1): A8 [Abstract].

[10] Debnath D, Dielehner N, Gunning KA. Guidelines, compliance, and effectiveness: a 12 months' audit in an acute district general healthcare trust on the two week rule for suspected colorectal cancer. Postgrad Med J 2002; 78(926): 748-51.

[11] Walsh S, Bruce C, Bennington S, Ravi S. The fourteen-day rule and colorectal cancer. Ann R Coll Surg Engl 2002; 84(6): 386-8.

[12] Eccersley AJ, Wilson EM, Makris A, Novell JR. Referral guidelines for colorectal cancer--do they work? Ann R Coll Surg Engl 2003; 85(2): 107-10.

[13] Chaudhri S, Reay E, Nair S, et al. Two week referrals for colorectal cancer: does it delay final diagnosis? Gut 2003; 52(Suppl 1): A147 [Abstract].

[14] Flashman K, O'Leary DP, Senapati A, Thompson MR. The Department of Health's "two week standard" for bowel cancer: is it working? Gut 2004; 53(3): 387-91.

[15] Trickett JP, Donaldson DR, Bearn PE, Scott HJ, Hassall AC. A study on the routes of referral for patients with colorectal cancer and its affect on the time to surgery and pathological stage. Colorectal Dis 2004; 6(6): 428-31.

[16] Barwick TW, Scott SB, Ambrose NS. The two week referral for colorectal cancer: a retrospective analysis. Colorectal Dis 2004; 6(2): 85-91.

[17] Davies RJ, Collins CD, Vickery CJ, Eyre-Brook I, Welbourn R. Reduction in the proportion of patients with colorectal cancer presenting as an emergency following the introduction of fast-track flexible sigmoidoscopy: a three-year prospective observational study. Colorectal Dis 2004; 6(4): 265-7.

[18] Glancy DG, Card M, Sylvester PA, et al. Fast-track barium enema: meeting the two-week wait rule for patients with suspected colorectal cancer. Colorectal Dis 2005; 7(3): 241-4.

[19] Chohan DP, Goodwin K, Wilkinson S, Miller R, Hall NR. How has the 'two-week wait' rule affected the presentation of colorectal cancer? Colorectal Dis 2005; 7(5): 450-3.

[20] Maruthachalam K, Stoker E, Chaudhri S, Noblett S, Horgan AF. Evolution of the two-week rule pathway--direct access colonoscopy vs outpatient appointments: one year's experience and patient satisfaction survey. Colorectal Dis 2005; 7(5): 480-5.

[21] Shenderey R, Prince M, Nylander D. More resources to implementation of the "two week rule" will not lead to diagnosis of colon cancer at an earlier stage. Gut 2005; 54(Suppl 2): A137 [Abstract].

[22] Sidhu R, Horoldt B, Fagg M, Donnelly M. Effect of 2 week wait guidelines on waiting times for colonoscopy. Gut 2005; 54(Suppl 2): A421 [Abstract].

[23] Maruthachalam K, Stoker E, Nicholson G, Horgan A. The two week rule for colorectal cancer:experience of a nurse led flexible sigmoidoscopy clinic in primary care. Gut 2006; 55(Suppl 2): A365 [Abstract].

[24] Barrett J, Jiwa M, Rose P, Hamilton W. Pathways to the diagnosis of colorectal cancer: an observational study in three UK cities. Fam Pract 2006; 23(1): 15-9.

[25] Rao GN, Basnyat P, Taffinder N, Hudson C, Insall R. Reducing surgical outpatient waiting is not the solution to meeting the 2005 colorectal cancer target. Colorectal Dis 2006; 8(2): 135-9.

[26] Smith RA, Oshin O, McCallum J, et al. Outcomes in 2748 patients referred to a colorectal two-week rule clinic. Colorectal Dis 2007; 9(4): 340-3.
[27] John SK, Jones OM, Horseman N, Thomas P, Howell RD, Fozard JB. Inter general practice variability in use of referral guidelines for colorectal cancer. Colorectal Dis 2007; 9(8): 731-5.

[28] Aljarabah M, Borley N, Goodman T, Wheeler J. Referral letters for two week wait for suspected colerectal cancer do not allow a straight-to-test pathway. Gut 2007; 56(Suppl 2): A132 [Abstract].

[29] Rai S, Kelly MJ. Prioritization of colorectal referrals: a review of the 2-week wait referral system. Colorectal Dis 2007; 9(3): 195202.

[30] Shaw AG, Simpson J, Tierney G, Goddard AF, Reynolds JR, Lund JN. Referral of patients with iron deficiency anaemia under the lower gastrointestinal two-week wait rule. Colorectal Dis 2008; 10(3): 294-7.

[31] Bevis PM, Donaldson OW, Card M, et al. The association between referral source and stage of disease in patients with colorectal cancer. Colorectal Dis 2008; 10(1): 58-62.

[32] John SK, George S, Howell RD, Primrose JN, Fozard JB. Validation of the lower gastrointestinal electronic referral protocol. Br J Surg 2008; 95(4): 506-14.

[33] Spencer H, Heeley R, Donnelly M. "Two week wait" guidelines for upper gastrointestinal cancer - do they work? Gut 2001; 48(Suppl 1): A21 [Abstract].

[34] Mahmood A, Millan-Smith J, Kang JY, Maxwell JD. Prospective analyis of the two week rule for urgent referral of suspected upper GI cancer. Gut 2001; 48(Suppl 1): a31 - a39 [Abstract].

[35] Lassman D, Eliott J, Taylor A, Green A, Grimley C. Service implications and success of the implementation of the two-week referral criteria for upper gastrointestinal cancers in a district general hospital. Gut 2002; 50(Suppl 2): A228 [Abstract].

[36] Loehry J, Smith T, Vyas S. Achieving the "two week standard" for suspected upper GI cancers: continuing pain with mimimal gain: a retrospective audit. Gut 2002; 50(Suppl 2): A366 [Abstract].

[37] Subramanian S, Lloyd D, Paulis A, et al. Few gastro-oesophageal malignancies are identified through two-week rule. Gut 2002; 50(Suppl 2): A404 [Abstract].

[38] Warner R, Das D. "The 2 week upper GI cancer rule" how successul is this? A retrospective audit in a district general hospital. Gut 2003; 52(Suppl 1): A323 [Abstract].

[39] Barbour J, Leonitadis G, Saeed A, Kadis S. Audit of the 2 week rule (TWR) for suspected upper gastrointestinal (UGI) cancer and the pathways to diagnosis. Gut 2003; 52(Suppl 1): A325 [Abstract].

[40] Aung M, Vuojic J, Anwar S, Shiwani M. Impact of 2 week wait referral on the management of upper gastrointestinal malignancy. Gut 2003; 52(Suppl 1): A326 [Abstract].

[41] Reilly A, Clark G, Horder E, Berry L, Johnson E, Denyer M. An audit of early referral for suspected upper GI cancer. Gut 2003; 52(Suppl 1): A428 [Abstract].

[42] Radbourne D, Walker G, Joshi D, et al. The 2 week standard for suspected upper GI cancers: its impact on cancer staging. Gut 2003; 52(Suppl 1): A430 [Abstract].

[43] Mohammed F, Shenoy A, Krishman N, et al. Has the implementation of the two week rule impacted on mortality in upper GI cancers? An audit at two district general hospitals. Gut 2004; 53(Suppl 3): A455 [Abstract].

[44] Kapoor N, Bassi A, Sturgess R, Bodger K. Predictive value of alarm features in a rapid access upper gastrointestinal cancer service. Gut 2005; 54(1): 40-5.

[45] Spahos T, Hindmarsh A, Cameron E, et al. Endoscopy waiting times and impact of the two week wait scheme on diagnosis and outcome of upper gastrointestinal cancer. Postgrad Med J 2005; 81(961): 728-30.

[46] Cairns A, Keating J, Brown C, et al. Impact of government guidelines on survival of patients with oesophageal carcinoma. Gut 2005; 54(Suppl 2): A208 [Abstract].

[47] $\mathrm{Ng} \mathrm{S}$, Pitcher M. The two week wait and upper gastrointestinal cancer: on target but missing the point? Gut 2005; 54(suppl 2): A417 [Abstract].

[48] Carty E, Barret H, Sawyerr A, Greaves R, Britt C, Alstead E. 2 week wait for upper GI cancer: are GPS getting the message? Gut 2005; 54(Suppl 2): A426 [Abstract].

[49] Moran G, Iyer H, Bailey A, Butterworth J. Is the two week cancer wait saving lives? A prospective follow up of patients diagnosed with oesophagogastric and pancreatic cancer in 2003. Gut 2006; 55(Suppl 2): A24 [Abstract]. 
[50] Dewar D, Chouhan M, Sagili V, et al. Declining prevalence of cancer in two week wait referrals for suspected upper gastrointestinal malignancy. Gut 2006; 55(Suppl 2): A25 [Abstract].

[51] Gera A, Evans R, Ede R. The changing pattern of referrals for upper gastrointestinal cancer 2001-5. Gut 2007; 56(Suppl 2): A246 [Abstract].

[52] Irving G, Chikwanda F, Morowski P, Kapur K, Shiwani M. The role of straight-to-test endoscopy for two-week wait referrals suspected of upper gastrointestinal malignancy. Gut 2008; 57(Suppl 1): A161 [Abstract].

[53] West NJ, Poullis AP, Leicester RJ. The NHS Bowel Cancer Screening Programme--a realistic approach with additional benefits. Colorectal Dis 2008; 10(7): 708-14.

[54] Martin JP, Gabe SM, Pitcher MC, Jacyna MR. Referral patterns to a district general hospital gastroenterology outpatient clinic: implications for the 'two-week target'. Int J Clin Pract 2002; 56(1): 26-8.

[55] Kiran PR, Glass RE. Duration of symptoms and spread of colorectal cancer: a short history does not mean early disease. Ann R Coll Surg Engl 2002; 84(6): 381-5.

[56] Raje D, La Touche S, Mukhtar H, Oshowo A, Ingham Clark C. Changing trends in the management of colorectal cancers and its impact on cancer waiting times. Colorectal Dis 2006; 8: 140-4.
[57] Cancer Research UK. Age-standardised mortality rates for CRC. 2009 Available from: http://info.cancerresearchuk.org/cancerstats/ types/bowel/mortality/?a=5441 [cited February 2009].

[58] Cancer Research UK. Agee-standardised mortality rates for gastric cancer. 2009 Available from: http://info.cancerresearchuk.org/ cancerstats/types/stomach/mortality/?a=5441 [cited February 2009].

[59] Cancer Research UK. Age-standardised mortality rates for oesophageal cancer. 2009 Available from: http://info.cancerresearchuk. org/cancerstats/types/oesophagus/mortality/?a=5441 [cited February 2009].

[60] NHS Modernisation Agency. Modernising Endoscopy Services - A practical guide to redesign. Leicester: NHS Modernisation Agency: 2003.

[61] Global Rating Scale. 2009 Available from: www.grs.nhs.uk [cited February 2009].

[62] The 18-week patient pathway. 2009 Available from: http://www. 18weeks.nhs.uk/Content.aspx?path=/ [cited February 2009].

(c) Thorne et al.; Licensee Bentham Open.

This is an open access article licensed under the terms of the Creative Commons Attribution Non-Commercial License (http://creativecommons.org/licenses/by-nc/3.0/) which permits unrestricted, non-commercial use, distribution and reproduction in any medium, provided the work is properly cited. 